\title{
Sexual Risk Behaviour among HIV-Positive Individuals in Clinical Care in Urban KwaZulu- Natal, South Africa
}

\author{
Susan M. Kiene \\ Brown University \\ Sarah Christie \\ University of Connecticut - Storrs \\ Deborah H. Cornman \\ University of Connecticut - Storrs \\ William A. Fisher \\ University of Western Ontario \\ Paul A. Shuper \\ University of Connecticut - Storrs \\ See next page for additional authors
}

Follow this and additional works at: https://opencommons.uconn.edu/chip_docs

Part of the Health Psychology Commons

\section{Recommended Citation}

Kiene, Susan M.; Christie, Sarah; Cornman, Deborah H.; Fisher, William A.; Shuper, Paul A.; Pillay, Sandy; Friedland, Gerald H.; and Fisher, Jeffrey D., "Sexual Risk Behaviour among HIV-Positive Individuals in Clinical Care in Urban KwaZulu-Natal, South Africa" (2006). CHIP Documents. 28.

https://opencommons.uconn.edu/chip_docs/28 
Authors

Susan M. Kiene, Sarah Christie, Deborah H. Cornman, William A. Fisher, Paul A. Shuper, Sandy Pillay, Gerald H. Friedland, and Jeffrey D. Fisher 
Title: $\quad$ Sexual Risk Behaviour among HIV-Positive Individuals in Clinical Care in Urban KwaZulu-Natal, South Africa

Running Head: $\quad$ Unprotected Sex among HIV+ South Africans

Authors:

Susan M. Kiene ${ }^{1}$, Sarah Christie ${ }^{1}$, Deborah H. Cornman ${ }^{1}$, William A.

Fisher $^{1,2}$, Paul A. Shuper ${ }^{1}$, Sandy Pillay ${ }^{3}$, Gerald H. Friedland ${ }^{4}$, \& Jeffrey

D. Fisher ${ }^{1}$

${ }^{1}$ Center for Health / HIV Intervention \& Prevention, Department of Psychology, University of Connecticut

${ }^{2}$ Departments of Psychology and Obstetrics and Gynaecology, University of Western Ontario

${ }^{3}$ Nelson Mandela School of Medicine, University of KwaZulu-Natal

${ }^{4}$ AIDS Program, Yale University School of Medicine

\section{Address correspondence and reprint requests to:}

Susan M. Kiene, Ph.D.

Assistant Professor of Medicine \& Community Health (Research)

The Warren Alpert Medical School of Brown University

593 Eddy Street, Plain St. Bldg

Providence, RI 02903

Sponsorship: $\quad$ This study was supported by the National Institutes of Mental Health (grant number RO1 MH59473) and by a development grant from the Center for Health/ HIV Intervention \& Prevention at the University of Connecticut. 


\begin{abstract}
Objectives: To assess the prevalence and predictors of unprotected sex among HIV+ individuals in clinical care in urban KwaZulu-Natal, South Africa.

Design: Cross-sectional survey of $152 \mathrm{HIV}+$ individuals attending a hospital-based HIV-clinic. Methods: Structured interviews were conducted by bilingual interviewers. Sexual risk behaviour in the preceding 3 months was assessed via event counts.

Results: In one of the first studies of its kind in South Africa we found that nearly half of the sample reported vaginal or anal sex during the preceding 3 months, and $30 \%$ of these patients reported unprotected vaginal or anal sex. Among sexually active patients, a total of 171 unprotected sex events were reported, $40 \%$ of which were with partners perceived to be HIVnegative or HIV-status unknown. Nine such partners were potentially exposed to HIV. Alcohol use during sex, being forced to have sex, sex with a perceived HIV+ partner, and sex with a casual partner predicted more unprotected sex, whereas HIV-status disclosure was related to less unprotected sex.
\end{abstract}

Conclusions: HIV+ individuals in clinical care in South Africa may engage in unprotected sex that place others at risk of HIV infection and themselves at risk for infection with STIs. With a national ARV rollout currently underway in South Africa, increasing numbers of HIV+ individuals are entering care. This affords a crucial opportunity to link HIV prevention with HIV care, an approach that aims to reduce transmission risk behaviour among HIV+ individuals and is consistent with international agencies’ current prevention priorities.

Keywords: Africa, Prevention of sexual transmission, sexual behaviour, risk factors, condoms, HIV seropositivity, unsafe sex 


\section{Introduction}

South Africa is facing a devastating HIV pandemic with nearly 5 million people or $16.2 \%$ of the population between the ages of 15 and 49, currently HIV-infected [2]. Reducing unprotected sex in this population, in part by linking HIV prevention with HIV clinical care, is recommended as a priority HIV/AIDS prevention strategy by UNAIDS [3], WHO [4] and the Global HIV Prevention Working Group [5].

At present, very little is known about the prevalence and predictors of unprotected sexual behaviour among HIV+ individuals in South Africa, and even less is known about this behaviour among HIV+ persons who are in HIV clinical care in this country. Moreover, the few studies that have examined unprotected sex among HIV+ individuals in South Africa have assessed it solely in relation to condom use or nonuse at the last sexual encounter [2,6,7]. Assessing unprotected sex using this approach yields a narrow and potentially misleading perspective on the magnitude of risk of transmission of HIV from those infected because it does not provide information about unprotected sex in terms of the numbers of unprotected sex events or the number of partners potentially exposed to HIV over meaningful intervals of time [8]. An alternative and potentially more informative measurement approach is to use event-counts in which participants are asked to indicate the number of times they engaged in intercourse with each of their partners over a specified time period, and how many of those intercourse events involved the use of a condom, thus yielding the number of intercourse events that were unprotected over a given interval of time [8].

In addition to measurement concerns, none of the studies in South Africa to date have examined unprotected sex among HIV+ individuals on antiretroviral therapy (ARV). Only one study examined correlates of unprotected sex among HIV+ individuals [6]. However, in addition 
to only measuring condom use at last intercourse, this study failed to assess disclosure and sexual partner characteristics, which may be important predictors of risk behaviour. With a national ARV rollout underway in South Africa [9,10], comprehensive information about unprotected sexual behavior among HIV+ individuals on ARV therapy is especially critical in order to know how to direct secondary prevention efforts. Prevention efforts in South Africa are also an important method to protect against risk compensation—or increases in unprotected sex due to reduced perceptions of the threat posed by HIV/AIDS (Cassell et al., 2006). Because an increasing number of HIV+ individuals are entering clinical care [9,10], there is now a critical opportunity to deliver HIV prevention interventions in the context of HIV care, to assist HIV+ individuals to avoid transmission of the virus and to protect themselves from sexually transmitted infections (STIs). Such interventions can be aided by carefully collected information concerning the prevalence and correlates of unprotected sex among HIV+ individuals on ARV therapy.

The present study fills this gap in the literature by measuring unprotected sex with event counts and by investigating the correlates of this behaviour among HIV+ individuals attending HIV clinical care in South Africa. The goals of the present study were to: 1) assess the prevalence of unprotected vaginal and anal sex amongst this population; and 2) examine whether levels of unprotected sex vary as a function of taking ARVs, partner type (steady vs. casual), perceived-partner HIV serostatus, alcohol use during sex, and other demographic and behavioural variables. 


\section{Methods}

\section{Study Population}

Participants were 152 HIV-infected patients attending an urban hospital-based HIV care clinic in KwaZulu-Natal, South Africa that provides highly subsidized treatment services. The University and the Hospital ethics boards approved the study’s procedures, and written informed consent was obtained from all participants. Participant demographics appear in Table 1.

\section{Measurement}

The in-depth structured individual interviews were conducted in a private room in either isi-Zulu or English. Unprotected sex was assessed separately for each of the 5 most recent sexual partners in the preceding 3 months, as relevant, with participants reporting the number of sexual events (vaginal, anal, and oral sex) with each partner, whether a condom was used for each type of sexual event (excluding oral sex), each partner's perceived HIV-serostatus (HIV-positive, HIV-negative, or unknown), the partner type (steady or casual), and whether or not they had disclosed their HIV-status to the partner [11]. Yes-no questions assessed if participants had disclosed their HIV-status to someone outside of the clinic and if they had been physically forced to have sex in the prior 3 months. Alcohol use during sex in the prior 3 months was assessed on a 5-point scale with 1 = 'never’ and 5 = 'always’ [12].

\section{Statistical Analyses}

A regression model was estimated using generalized estimating equations (GEE) and specifying a Poisson distribution, simultaneously entering demographic and behavioral variables as potential predictors of the number of unprotected (vaginal or anal) sex events among sexually active participants. GEE were used to account for the correlated nature of the data (i.e., repeated observations for those reporting more than one partner) as well as the Poisson distribution that is 
appropriate for count data [13-15]. Results from this model and descriptive statistics for the demographic and behavioural variables that were significant correlates of unprotected sex appear in Table 2. Data were analyzed using SPSS version 11.5 (SPSS Inc., Chicago, IL, USA) and HLM version 6.02 (Scientific Software International Inc., Lincolnwood, IL, USA) for Windows.

\section{Results}

\section{Prevalence of Unprotected Sexual Behavior}

Approximately half (47\%) of the $152 \mathrm{HIV}+$ patients reported having vaginal or anal sex in the past 3 months for a total of 676 vaginal and 12 anal sex events, while only $3 \%$ reported having oral sex in the past 3 months for a total of 17 oral sex events. Of the sexually active patients $(\mathrm{N}=71), 23(30 \%)$ reported one or more unprotected vaginal or anal sex events for a total of 171 unprotected sex events in the prior 3 months with 27 different partners. Sixty-seven (39.2\%) of the unprotected sex events were with partners perceived to be HIV-negative or HIVstatus unknown with a total of nine such partners potentially exposed to HIV. Only four (5.6\%) sexually active participants reported having more than one sexual partner. There were no gender differences in sexual behaviour.

\section{Predictors of Unprotected Sexual Behaviour}

According to the GEE model, those who used alcohol during sex during the prior 3 months reported 3 times more unprotected sex events, those reporting forced sex in the prior 3 months reported greater than 3 times more unprotected sex events, individuals who had sex with a perceived HIV+ partner had 2.5 times more unprotected sex events, individuals who had sex with a casual partner had 3.5 times more unprotected sex events, and individuals who disclosed their HIV status to someone outside the clinic reported only one fourth as many unprotected sex events as those who had not disclosed to someone outside the clinic. Event rate ratios with 
confidence intervals and the mean numbers of unprotected sexual events based on these factors are given in Table 2. There were no effects of gender, age, length of time since HIV diagnosis, ethnicity, SES, employment, education level, urban vs. rural residence, taking ARVs, reported STI diagnosis in prior 3 months, or for disclosure of HIV-status to the partner on levels of risk behaviour.

\section{Discussion}

These results indicate that unprotected sex occurs at nontrivial rates among HIV+ individuals in clinical care in South Africa, with 30\% of those who were sexually active--15\% of all those sampled--having had unprotected vaginal or anal sex. Some $40 \%$ of the reported unprotected sex events occurred with perceived HIV-negative or status unknown partners, which may be a conservative estimate because perceptions of a partner's HIV status are often speculative and inaccurate [16-18]. Moreover, HIV+ individuals remain at risk for STIs, as evidenced in our findings, and consistent with overall high prevalence of STIs in South Africa [19]. Overall, these findings highlight the need for the development and implementation of HIV prevention interventions for HIV-infected individuals in South Africa. Such interventions can be delivered efficiently in tandem with newly available HIV treatment and care in this country $[9,10]$. In addition, linking prevention to STI treatment for HIV+ individuals would be useful for reaching HIV+ individuals who are engaging in unprotected sexual behaviors.

The finding that those who reported recent forced sex had higher rates of unprotected sex is an important acknowledgement of the power dynamics and circumstances that might affect one's ability to practice safer behaviour [25,26], although perplexingly this finding did not differ by gender. Even though alcohol use in our sample was relatively low, its use in sexual situations predicted more unprotected sex and therefore HIV prevention interventions with HIV+ patients 
should address this critical risk factor. Status disclosure to a partner was not related to lower levels of unprotected sex, although disclosure to someone outside of the clinic was related to lower levels of unprotected sex. This lends support to promoting general HIV-status disclosure. Given the existence of widespread HIV stigma in South Africa, we note that individuals must carefully consider the decision to disclose. However, disclosure may become more viable as stigma lessens with the current ARV rollout [27]. Contrary to speculation about the impact of ARVs on unprotected sexual behaviour in sub-Saharan Africa [28], patients who reported taking ARVs engaged in no more unprotected sex than those who were not taking ARVs. Many of our patients had initiated ARV therapy within the past 2 months, however, and it is unknown what the effect of ARVs will be on patients' unprotected sexual behaviours longitudinally.

This study represents one of the first investigations of the prevalence and correlates of unprotected sex in an HIV+ clinical care population in South Africa. It is also the first to assess the levels of unprotected sexual behaviour among this population in terms of the number of unprotected sex events, and the first to examine unprotected sex among HIV+ South Africans taking ARVs. Not only is this study the first of its kind in South Africa but it is one of only a small number of such studies in Africa.

With a national ARV rollout currently underway in South Africa, increasing numbers of HIV + individuals are entering clinical care [9,10], affording the opportunity to deliver HIV prevention interventions in this setting that will assist HIV+ individuals to avoid transmission of the virus to others and protect themselves from STIs. This approach is advocated by international agencies [3-5,29] as an essential HIV prevention strategy because it takes advantage of the efficiencies and potential synergy of linking treatment and prevention. Such an approach is especially relevant because the linkage provides opportunities for risk reduction interventions to 
be delivered to HIV+ patients repeatedly and routinely over the course of clinical care, in a safe and supportive environment. 


\section{Acknowledgements}

The authors thank the participants in the study and the following individuals for their roles in the project: Linda Lodge, Aleeta Sabasaba, Monty Thomas, Musa Cele, and the clinic counsellors as well as Drs. Helga Holst \& Janet Giddy for their support of the project. 


\section{References}

1. UNAIDS. 2004 report on the global HIV/AIDS epidemic: 4th global report. Geneva, Switzerland. Available at: http://www.unaids.org/bangkok2004/GAR2004_html/GAR2004_00_en.htm.

2. Shisana O, Rehle T, Simbayi L C, Parker W, Zuma K., Bhana A. et al. South African National HIV Prevalence, HIV Incidence, Behavior and Communication Survey, 2005. Cape Town, South Africa: Human Sciences Research Council Publishers. Available at: http://www.hsrcpublishers.co.za/e-books

3. UNAIDS. Intensifying HIV prevention: UNAIDS policy position paper, September 2005. Geneva, Switzerland. Available at: http://www.unaids.org/html/pub/governance/pcb04/pcb_17_05_03_en_pdf.pdf

4. WHO. 3 by 5 December 2003 progress report though June 2004. Geneva, Switzerland. Available at: www.who.int/entity/3by5/en/Progressreport.pdf.

5. Global HIV Prevention Working Group. HIV prevention in the era of expanded treatment access, June, 2004. Available at: http://www.kff.org/hivaids/hiv061004pkg.cfm

6. Olley BO, Seedat S, Gxamza F, Reuter H, Stein DJ. Determinants of unprotected sex among HIV-positive patients in South Africa. AIDS Care. 2005; 17:1-9.

7. Shisana O, Peltzer KF, Zungu-Dirwayi NP, Louw J (eds). The health of our educators: a focus on HIV/AIDS in South African public schools, 2004/5 survey. Cape Town: HSRC Press, 2005. Available at: http://www.hsrcpress.ac.za/full_title_info.asp?id=2082

8. Schroder KEE, Carey, MP, Vanable, PA. Methodological challenges in research on sexual risk behavior: I. Item content, scaling, and data analytic options. Ann Behav Med. 2003; 26:76-103. 
9. RSA Department of Health. Operational Plan for Comprehensive HIV and AIDS Care, Management, and Treatment for South Africa. Pretoria, South Africa, November 19, 2003. Available at: http://www.info.gov.za/otherdocs/2003/aidsplan.pdf.

10. RSA Department of Health. Monitoring Review: Progress Report on the Implementation of the Comprehensive HIV and AIDS Care, Management and Treatment Programme. Pretoria, South Africa, September, 2004. Available at: http://www.doh.gov.za/docs/reports/2004/hivaids-care/monitorreview.pdf

11. Fisher JD, Fisher WA, Cornman DH, Amico RK, Bryan A, Friedland GH. Cliniciandelivered intervention during routine clinical care reduces unprotected sexual behavior among HIV-infected patients. J Acquir Immune Defic Syndr. 2006; 41:44-52.

12. Dawson, D. A. Methodological issues in measuring alcohol use. Bethesda, MD: National Institute on Alcohol Abuse and Alcoholism, 2003. Available at: http://pubs.niaaa.nih.gov/publications/arh27-1/18-29.htm

13. Cohen J, Cohen P, West SG, Aiken LS. Applied multiple regression/correlation analysis for the behavioral sciences. $3^{\text {rd }}$ ed. Mahwah, NJ: Lawrence Erlbaum Associates; 2003.

14. Edwards, LJ. Modern statistical techniques for the analysis of longitudinal data in biomedical research. Pediatr Pulmonol. 2000; 30:330-44.

15. McCullagh P, Nelder JA. Generalized linear models. $2^{\text {nd }}$ ed. New York: Chapman and Hall; 1989.

16. Carballo-Dieguez A, Remien RH, Dolezal C, Wagner G. Reliability of sexual behavior self-reports in male couples of discordant HIV status. J Sex Res. 1999; 36:152-58.

17. Fisher JD, Misovich SJ, Kimble DL, Weinstein B. Dynamics of HIV risk behavior in HIV-infected injection drug users. AIDS Behav. 1999; 3:41-57. 
18. Fisher JD, Wilcutts DK, Misovich SJ, Weinstein B. Dynamics of sexual risk behavior in HIV-infected men who have sex with men. AIDS Behav. 1998; 2:101-13.

19. Johnson LF, Coetzee DJ, Dorrington RE. Sentinel surveillance of sexually transmitted infections in South Africa: a review. Sex Transm Infect. 2005; 81:287-93.

20. Anzala AO, Simonsen JN, Kimani J, Ball BT, Nagelkerke NJD, Rutherford J, et al. Acute sexually transmitted infections increase human immunodeficiency virus type 1 plasma viremia, increase plasma type 2 cytokines, and decrease CD4 cell counts. J Infect Dis. 2000; 182:459-66.

21. Klausner JD, Kent CK. HIV and sexually transmitted diseases. Latest views on synergy, treatment, and screening. Postgrad Med. 2004; 1154:79-84.

22. Reynolds SJ, Risbud AR, Shepherd ME, Zenilman JM, Brookmeyer RS, Paranjape RS, et al. Recent herpes simplex virus type 2 infection and the risk of human immunodeficiency virus type 1 acquisition in India. $J$ Infect Dis. 2003; 187:1513-21.

23. Serwadda D, Gray RH, Sewankambo NK, Wabwire-Mangen F, Chen MZ, Quinn TC, et al. Human immunodeficiency virus acquisition associated with genital ulcer disease and herpes simplex virus type 2 infection: A nested case-control study in Rakai, Uganda. $J$ Infect Dis. 2003; 188:1492-97.

24. Wright PW, Hoesley CJ, Squires KE, Croom-Rivers A, Weiss HL, Gnann JW Jr. A prospective study of genital herpes simplex virus type 2 infection in human immunodeficiency virus type 1 (HIV-1)-seropositive women: correlations with CD4 cell count and plasma HIV-1 RNA level. Clin Infect Dis. 2003; 36: 207-11. 
25. Dunkle KL, Jewkes RK, Brown HC, Gray GE, McIntryre JA, Harlow SD. Gender-based violence, relationship power, and risk of HIV infection in women attending antenatal clinics in South Africa. Lancet. 2004; 363:1415-21.

26. Wojcicki JM. "She drank his money”: Survival sex and the problem of violence in taverns in Gauteng Province, South Africa. Med Anthropol Q. 2002; 16:267-93.

27. Stein J. The impact of antiretroviral (ARV) provision on HIV/AIDS prevention. AIDS Bulletin. 2005; 14.

28. Marseille E, Hofmann PB, Kahn JG. HIV prevention before HAART in sub-Saharan Africa. Lancet. 2002; 359:1851-6.

29. Centers for Disease Control and Prevention. Advancing HIV Prevention: New strategies for a changing epidemic, 2003. Available at: http://www.cdc.gov/hi/partners/ahp_program.htm 
Table 1. Demographic characteristics of HIV+ patients attending an HIV care clinic in urban South Africa

No. $(\%)$

Gender

Male

$65(42.8)$

Female

$87(57.2)$

Age

$<30$

$42(27.6)$

$30-39$

$80(52.6)$

$\geq 40$

30 (19.7)

Employed

Yes

45 (29.6)

No

$103(67.8)$

SES $^{\mathrm{a}}$

Not enough money for food

$85(56.7)$

Enough for food, but not for other basics

25 (16.7)

Enough for food \& basics but not for other things

32 (21.3)

Enough for most important things but no luxury goods

$6(4.0)$

Some money for luxury goods

2 (1.3)

Ethnicity

Zulu

139 (91.4)

Other African ethnicity

$6(4.0)$

Indian

3 (2.0)

Coloured (mixed race)

$1(0.7)$

White

$1(0.7)$

Other

$2(1.3)$

Residence

Urban

118 (77.6)

Rural

33 (21.7) 
Education

$<$ high school

$67(44.1)$

high school

$66(43.4)$

$>$ high school

$19(12.5)$

Marital Status

Single

$120(78.9)$

Married

27 (17.8)

Widowed

4 (2.6)

Length of time since HIV diagnosis

$<1$ year

65 (42.8)

$1-2$ years

44 (28.9)

$>2$ years

43 (28.3)

Taking ARVs

Yes

$114(75.0)$

No

$35(23.0)$

STI diagnosis in past 3 months

Yes

$53(34.9)$

No

99 (65.1)

${ }^{\text {a }}$ SES was assessed using a measure utilized in a national representative sample of individuals in South Africa [2]. 
Table 2. Descriptive statistics and predictors of sexual risk events among sexually active participants from GEE Poisson Regression Analysis

\begin{tabular}{|c|c|c|c|c|c|}
\hline \multirow[b]{2}{*}{ Variable } & \multirow[b]{2}{*}{$\%$ Yes } & \multicolumn{2}{|c|}{ Mean \# Risk Events } & \multirow[b]{2}{*}{ Event Rate Ratio (CI) } & \multirow[b]{2}{*}{$\mathrm{t}_{(65)}$} \\
\hline & & Yes & No & & \\
\hline Alcohol use during sex ${ }^{a}$ & 7.0 & 13.33 & 4.35 & $3.08(1.77-5.35)$ & $4.05 * * *$ \\
\hline Forced sex & 8.5 & 14.01 & 4.14 & $3.37(1.56-7.78)$ & $4.30 * * *$ \\
\hline HIV-positive partner & 49.3 & 11.59 & 4.95 & $2.34(1.05-5.20)$ & $2.12 *$ \\
\hline Casual partner & 9.9 & 14.15 & 4.06 & $3.48(1.56-7.78)$ & $3.09 * * *$ \\
\hline Disclosed HIV-status & 97.2 & 3.74 & 15.64 & $.24(.15-.39)$ & $5.99 * * *$ \\
\hline
\end{tabular}

$* p<.05, * * p<.01, * * * p<.001$. Mean risk events are calculated from the GEE model estimates and represent the number of sexual risk events in the prior 3-months.

${ }^{a}$ Alcohol use, although assessed with a continuous measure, was reported infrequently and was thus positively skewed and was therefore dichotomised into "alcohol use during sex" and "no alcohol use during sex." 